\title{
Desplugando: Ensinando Conceitos de Computação na Educação Básica
}

\author{
Givanaldo Rocha de Souza, Maria Alice Rodrigues Marinho, Vivianne Patrícia \\ Medeiros Azevedo, William Wonder Fagundes de Faria
}

Instituto Federal de Educação, Ciência e Tecnologia do Rio Grande do Norte (IFRN), Campus Parnamirim - Brasil

givanaldo.rocha@ifrn.edu.br, alicermarinho@hotmail.com, \{qfvivimedeiros, wonderwilliam3\} @gmail.com

\begin{abstract}
This article presents the experience report of Desplugando extension project, which consists in applying playful, non-computer activities, providing computer teaching in public schools whose laboratories are precarious. The project aims to show that computer education can be offered even under unfavorable structural conditions and warns of the need to include computer education in basic education. At the end of the project, we could prove that the students absorbed the taught content, as well as being enthusiastic about the activities.
\end{abstract}

Resumo. Este artigo apresenta o relato de experiência do projeto de extensão Desplugando, que consiste em aplicar atividades sem uso de computador, lúdicas, proporcionando o ensino de computação em escolas públicas cujos laboratórios são precários. O projeto busca incentivar que o ensino de computação pode ser ofertado mesmo em condições desfavoráveis de estrutura, além de alertar para a necessidade da inclusão do ensino de computação na educação básica. Ao final do projeto, pudemos comprovar que os alunos absorveram o conteúdo ministrado, além de se mostrarem entusiasmados com as atividades.

\section{Introdução}

A computação pode ser definida como a busca de uma solução para um problema a partir de entradas de dados e por meio de um algoritmo. É um subcampo da ciência da computação matemática e que durante centenas de anos foi executada com caneta e papel, giz, ardósia, ou somente mentalmente, por vezes com o auxílio de tabelas, ou utensílios artesanais. Segundo Amaral et al. (2014, p. 1475) a computação pode ser entendida como a ciência que estuda: [...] Algoritmos, Complexidade Computacional, Organização de Computadores, Linguagens de Programação, Redes de Computadores, Banco de Dados, Sistemas Operacionais, entre outros. [...]. Segundo Wing (2006), o pensamento computacional é uma habilidade fundamental para todos, não apenas para cientistas da computação. Além de aprender a ler, escrever e calcular, deveríamos adicionar o pensamento computacional na capacidade analítica de cada criança.

Hoje em dia, os computadores estão presentes em nossa vida de uma forma nunca vista anteriormente. Seja em casa, na escola, na faculdade, na empresa ou em qualquer outro lugar, eles estão sempre entre nós. $\mathrm{O}$ ensino de programação, além de ajudar a pensar e desenvolver o raciocínio lógico, faz com que os alunos tenham uma capacidade ainda maior para resolver problemas que são encontrados não apenas nos códigos, é uma porta de entrada para um mundo com novas possibilidades [Souza et al. 2019]. 
Dado isso, além dos avanços tecnológicos presenciados nas últimas décadas, conhecimentos mais avançados na área de Informática geram cada vez mais oportunidades para pessoas de diferentes idades. Todavia, apesar da tecnologia estar cada vez mais presente na vida de todos, não há uma disciplina na grade curricular obrigatória das escolas públicas do ensino básico que trate e aprimore os conhecimentos dos alunos acerca da computação. Além disso, as escolas, em sua grande maioria, contam com laboratórios de informática em situação precária ou destruídos [Souza et al. 2016].

O projeto de extensão Desplugando visa o ensino da Ciência da Computação sem o uso de computadores, baseado no livro "Computer Science Unplugged" [Bell et al. 2015], que apresenta diversas atividades que podem ser realizadas com crianças e adolescentes para o ensino da lógica computacional. Além desses conhecimentos, as oficinas e as atividades propostas pelo projeto tratam de assuntos presentes nas matérias de base curricular obrigatória, criando assim uma multidisciplinaridade entre a sala de aula e o projeto. A metodologia utilizada nesse relato de experiência é baseada na pesquisa-ação [Lewin 1946, Tripp 2005], por meio da observação das atividades realizadas pelos alunos, com uma avaliação sobre a experiência dos mesmos no processo, visando a melhoria das ações. Os resultados obtidos mostraram uma boa receptividade do projeto, além de ter despertado o interesse dos alunos pela área de computação.

As seções subsequentes do artigo estão organizadas conforme descrito a seguir. $\mathrm{Na}$ seção 2, descrevemos sobre o pensamento computacional, na seção 3 descrevemos sobre o uso da computação desplugada e na seção 4 descrevemos a metodologia utilizada. Na seção 5 descrevemos a avaliação usada no projeto para termos um retorno dos alunos e, finalmente, na seção 6 descrevemos as considerações finais.

\section{Pensamento computacional e computação desplugada}

Os avanços da tecnologia vêm causando uma grande revolução no século XXI e o uso de smartphones e similares tornou-se comum. Entretanto, é notável que a educação no Brasil ainda não sabe como conectar as novas tecnologias com a educação tradicional. O Brasil está localizado na penúltima posição de qualidade na Educação, de acordo com o ranking elaborado com base em dados divulgados pela Organização para a Cooperação e Desenvolvimento Econômico (OCDE) [Guia do Estudante 2019]. Diante desse ranking, podemos observar que, devido aos baixos investimentos em educação básica, temos escolas em situações precárias, monótonas e pouco atrativas tanto para crianças como para adolescentes, que tem como resultado a desistência ou desinteresse dos jovens.

Países como a Finlândia, que ocupa o primeiro lugar do ranking apresentado, possuem modelos de sucesso de como conectar, desde cedo, o ensino tradicional à tecnologia e raciocínio lógico. Os Finlandeses acreditam que é necessário ensinar codificação e programação desde a mais tenra idade e lá, essas matérias, já fazem parte da grade curricular obrigatória [Castro 2017]. O Brasil poderia seguir esse modelo de sucesso e fazer uso do ensino da lógica e do pensamento computacional para ensinar aos jovens.

Atualmente, devido à falta de investimento e manutenção, não é possível realizar aulas nos laboratórios de Informática em grande parte das escolas públicas estaduais e municipais. Dado isso, como forma de solução barata e eficaz, podemos utilizar técnicas de ensino do pensamento computacional por meio de atividades dinâmicas sem o uso de computadores, denominado como Computação Desplugada. Vale salientar que, com melhorias nas estruturas e investimentos em laboratórios, a educação pode fazer uso da 
mesma não como solução única, mas para uma junção e melhoria do ensino em conjunto de aulas práticas. A Computação Desplugada surge com o objetivo de ensinar os fundamentos da Ciência da Computação sem a necessidade de computadores. Assim, com as "atividades desplugadas", há uma facilidade para a aplicação em escolas com infraestrutura precárias, já que as mesmas independem do uso de qualquer tipo de hardware.

De acordo com Romero, Vallerand e Nunes (2019), essas atividades que estimulam o pensamento computacional estão ligadas a melhorias na criatividade, produtividade e inventividade. Com essas atividades, temos o desenvolvimento da aprendizagem cooperativa, que é a capacidade de desenvolver um entendimento compartilhado e trabalhar de forma coordenada com várias pessoas para atingir um objetivo comum, além de melhorias nas resoluções de problemas.

\section{Trabalhos relacionados}

$\mathrm{Na}$ literatura, temos vários artigos que abordam a computação desplugada. A maioria deles descrevem relatos de experiência em escolas da rede pública de ensino, seja no ensino médio ou no ensino fundamental.

Marinho et al. (2018) descrevem um relato de experiência vivenciado no Programa Institucional de Bolsas de Iniciação à Docência (PIBID), nos anos de 2015 e 2016, na Escola Estadual Prof ${ }^{a}$ Ana Julia de Carvalho Mousinho, em Natal - RN, por meio da utilização da computação desplugada e da programação em blocos usando Scratch para turmas do ensino médio. A experiência relatada mostrou que, com o uso da computação desplugada, os alunos se sentiam desafiados a resolver os problemas propostos e demonstraram melhor compreensão da lógica de programação na execução das atividades ao longo das oficinas.

Bezerra et al. (2017) descrevem um relato do uso da computação desplugada com alunos do ensino médio da rede pública de ensino em João Pessoa - PB e como as atividades desplugadas contribuem no processo de aprendizagem dos conceitos de computação.

Lopes e Ohashi (2019) descrevem um estudo teórico-prático sobre o pensamento computacional utilizando a computação desplugada com alunos do ensino fundamental da Escola Municipal Dr. José João de Melo, em Castanhal - PA. Ao final da pesquisa, chegouse à conclusão que o uso da computação desplugada estimula o desenvolvimento de habilidades do pensamento computacional.

Bell et al. (2009) descrevem em seu artigo como a computação desplugada se tornou popular na Nova Zelândia, por meio do projeto Unplugged da Universidade de Canterbury, bem como desenvolvimentos e adaptações para o ensino tanto local quanto internacional, com materiais traduzidos em japonês, italiano, alemão, espanhol, dentre outros idiomas.

\section{Metodologia do projeto}

A metodologia utilizada é baseada na pesquisa-ação [Lewin 1946, Tripp 2005], por meio da observação das atividades realizadas pelos alunos, com avaliação sobre a experiência dos mesmos no processo, visando a melhoria das ações futuras. Definiu-se como público-alvo os alunos do $5^{\circ}$ ano do ensino fundamental da Escola Estadual Arnaldo Arsênio de Azevedo, mais conhecida como CAIC Parnamirim e localizada na cidade de Parnamirim-RN. As oficinas foram aplicadas com 95 alunos, divididos em três turmas. Como o laboratório de Informática da escola estava deteriorado e obsoleto, sem condições de uso, optou-se pela aplicação da computação desplugada, ao invés da programação em blocos utilizada por Souza 
et al. (2019) em um projeto anterior em uma escola municipal também na cidade de Parnamirim-RN.

Foram realizadas reuniões com a diretoria e traçado um cronograma de ações. É importante destacar que foi a direção da escola quem definiu que os alunos do $5^{\circ}$ ano do ensino fundamental, três turmas do turno matutino, é quem iriam participar das oficinas, baseado em questões de horários de aula e disponibilidade dos professores de cada turma. Como forma de introdução, foi realizada uma palestra acerca da importância da área de Informática e da programação de computadores. Após a palestra, foi dado início às oficinas de computação desplugada, onde os alunos trabalharam na construção do conhecimento em computação colocando "a mão na massa" e fazendo descobertas, seguindo as ideias do construcionismo de Papert e Harel (1991), com a diferença de não usarem o computador. Muitas dessas escolas possuem laboratório subutilizados ou mesmo em desuso, necessitando da reativação desse importante espaço escolar de aprendizagem [Souza et al. 2016]. Contudo, há entraves de diversas naturezas que dificultam a recuperação dos laboratórios. Assim, para que os alunos não fiquem sem acesso ao mundo da computação, a computação desplugada se encaixa como uma ferramenta adequada.

Ao todo, foram aplicadas seis atividades desplugadas ao longo do ano, com um encontro semanal de 45 minutos por turma. Como forma de demonstração, apresentaremos quatro atividades que foram realizadas com os alunos: A primeira propõe o ensino dos números binários através de cartões em que, de acordo com o número escolhido, abaixamos ou não as cartas e fazemos assim a transformação, sem contas, de decimal para binário (Figura 1). A segunda atividade foi realizada após uma aula sobre pixels e a forma de armazenamento das imagens nos dispositivos eletrônicos, na mesma os alunos devem pintar os quadrados de acordo com os números representados ao lado (Figura 2). A atividade número 3 foi realizada após a explicação sobre a forma de otimização de memória, em que a mesma tem o objetivo de minimizar as repetições presentes no texto (Figura 3). Por último, a quarta atividade foi realizada após uma introdução de redes de computadores, em que os alunos realizam caminhos diferentes de acordo com a ordem numérica para a formação de uma sequência (Figura 4).

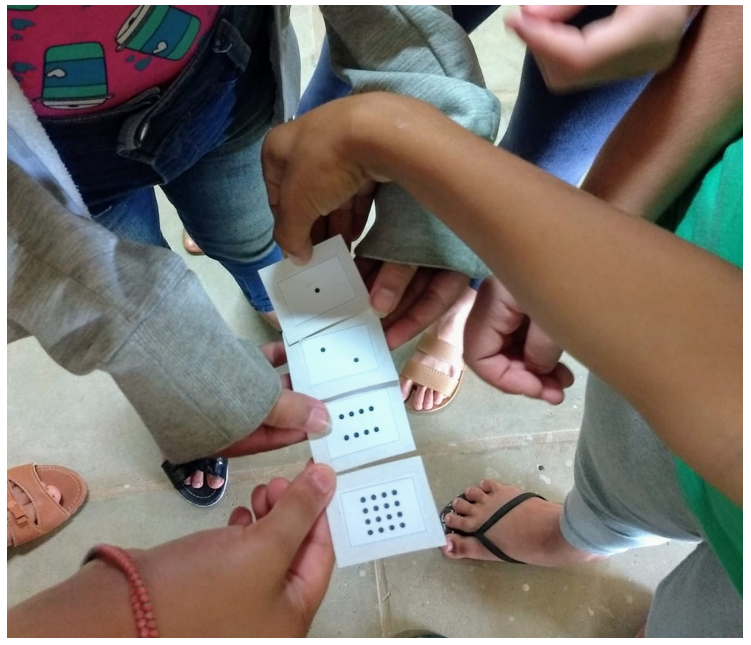

Figura 1. Números Binários.

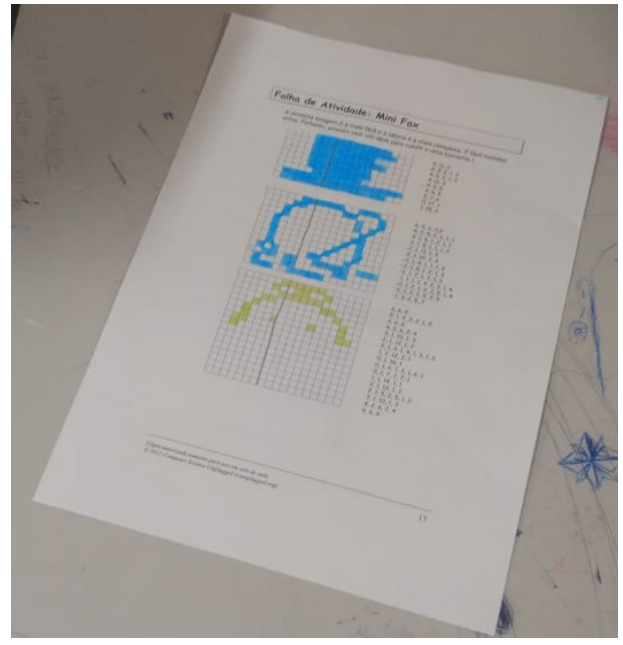

Figura 2. Representação de imagens 


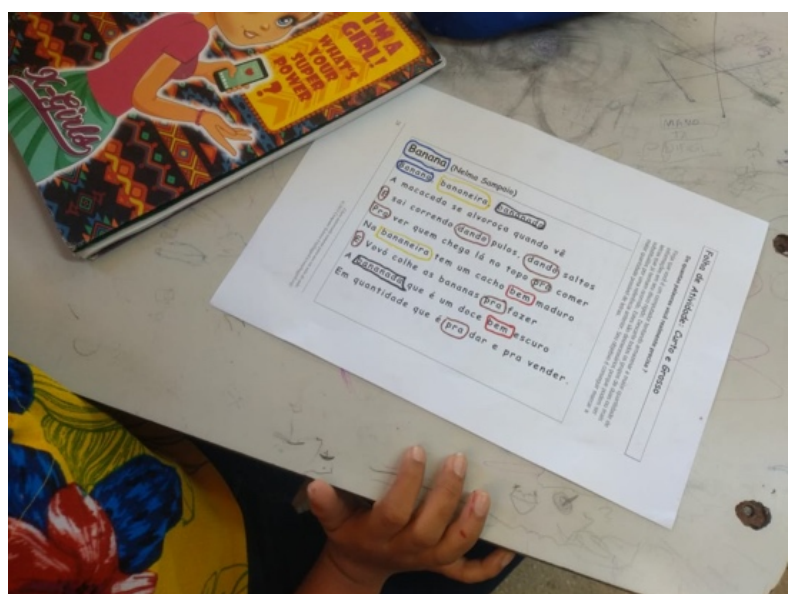

Figura 3. Compressão de Texto

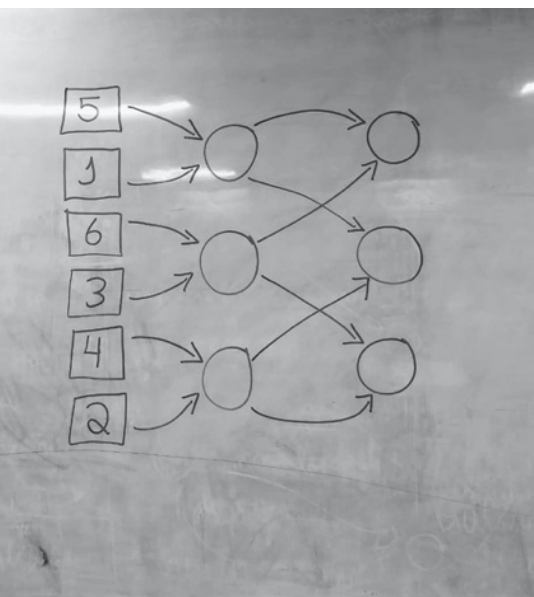

Figura 4. Redes de Ordenação

\section{Avaliação e resultados}

Antes de iniciarem as oficinas, um questionário foi aplicado junto aos alunos. O objetivo era saber como era o acesso deles ao celular e ao computador. Os questionários aplicados foram respondidos por 64 alunos. Observando a Figura 5, notamos que a utilização do celular é mais comum do que a utilização do computador. Observem também que mais da metade dos alunos nunca utilizaram um computador. Assim, já podemos inferir que uma atividade em laboratório de informática demandaria maior tempo de adaptação dos alunos.
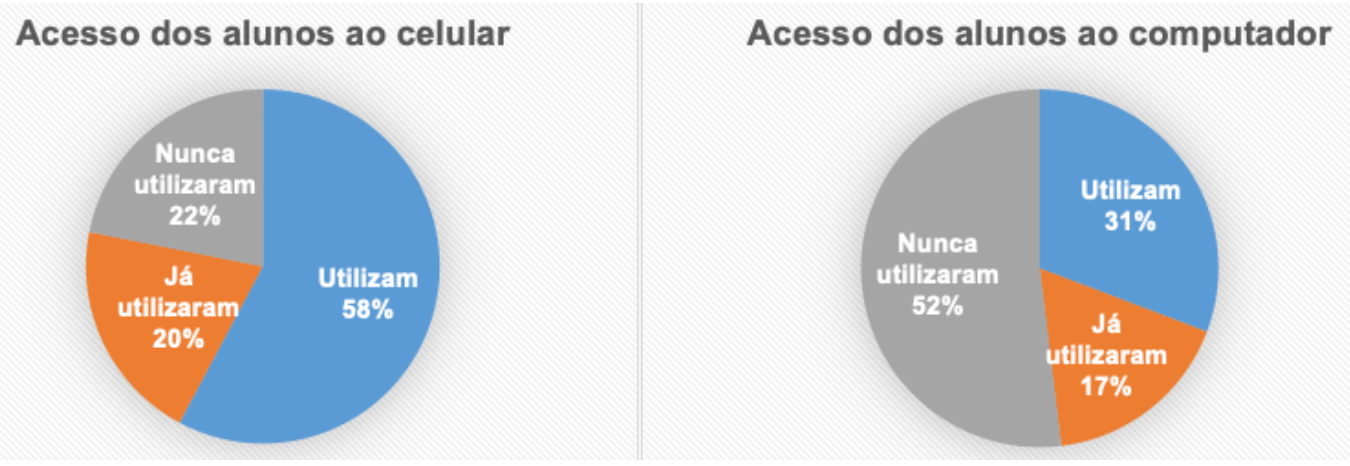

Figura 5. Uso de celular e computador pelos alunos

Ao observarmos as correções de algumas das atividades, sendo as duas iniciais relacionadas ao aprendizado dos números binários e a última com ênfase no estudo dos pixels, foram encontrados resultados distintos uns dos outros. Como mostrado na Figura 6, nota-se que nas atividades relacionadas aos números binários (Figuras 7 e 8) os alunos se saíram muito bem, sendo a atividade 01 a de maior destaque, onde os alunos obtiveram $92,3 \%$ de atividades totalmente certas, $7,7 \%$ de atividades totalmente erradas e $0 \%$ de atividades com erros e acertos juntos. Já na segunda tarefa, o número de atividades totalmente certas ficou com um índice de $88 \%$. Em contrapartida, as tarefas com erros subiram um pouco, tendo uma porcentagem de $8 \%$, e as atividades que possuía erros e acertos juntos representavam $4 \%$ do total de atividades, conforme os dados apresentados na Figura 6 . Os alunos tiveram aulas de matemática básica antes de iniciar o assunto de conversão de decimal para binário, justamente para revisar as operações básicas, principalmente a divisão, bastante utilizada na conversão de unidades. 


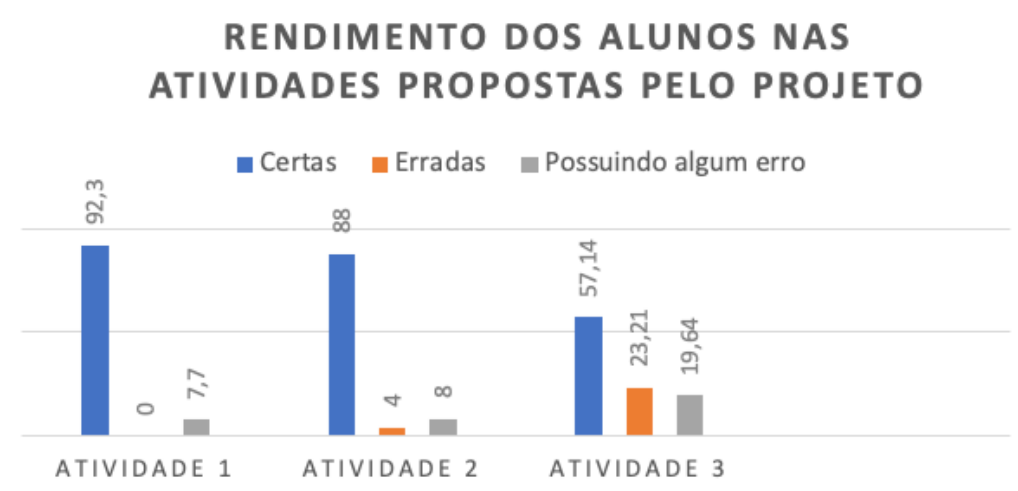

Figura 6. Gráfico referente as atividades 01,02 e 03

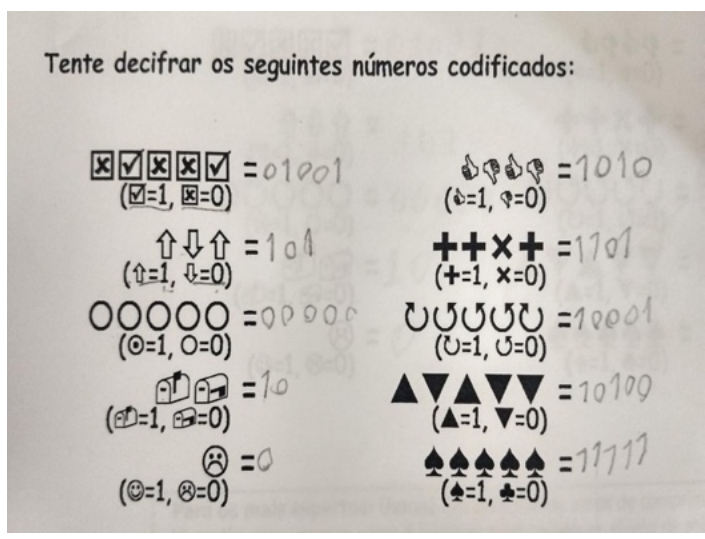

Figura 7. Atividade 01

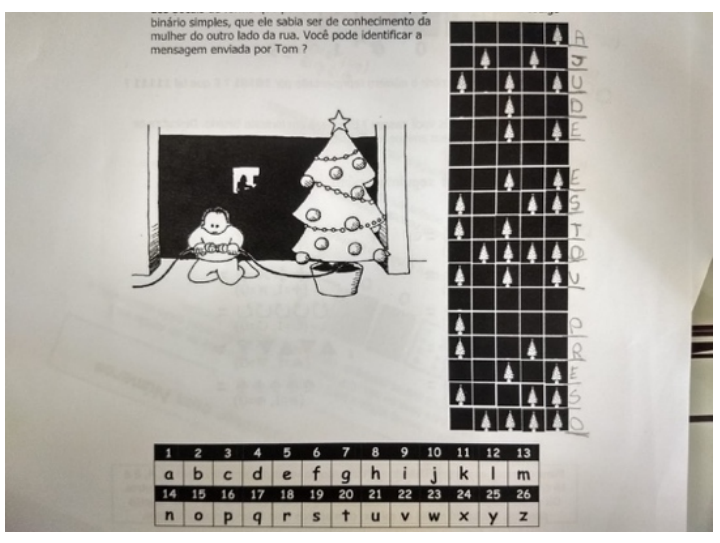

Figura 8. Atividade 02

A última tarefa, que tinha como conteúdo os estudos dos pixels (Figura 9), teve um rendimento um pouco abaixo em relação as atividades relacionadas ao aprendizado dos números binários. Entretanto, nessa atividade também alcançamos um bom rendimento com os alunos do projeto. Estas atividades tinham como objetivo ampliar os conhecimentos dos estudantes na área da computação, como também melhorar os seus raciocínios lógicos, aproveitando assim o ambiente escasso de computadores devido à falta de estrutura encontrada na escola.

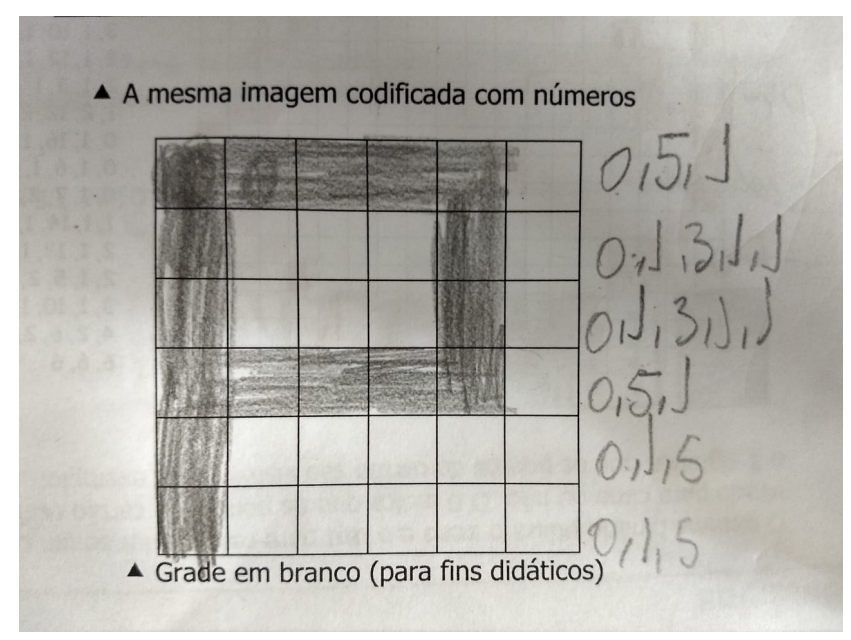


Figura 9. Atividade 03

A avaliação do projeto foi realizada por meio de um formulário impresso com quatro perguntas objetivas e, ao final, foi deixado um espaço para os alunos escreverem sugestões e críticas. De um total de 95 alunos participantes do projeto, 64 responderam ao questionário.

Na primeira pergunta, cada aluno deveria marcar o que achou do projeto. Na Figura 10 é mostrado o resultado em valores percentuais. O projeto foi considerado satisfatório para $96 \%$ dos alunos respondentes.

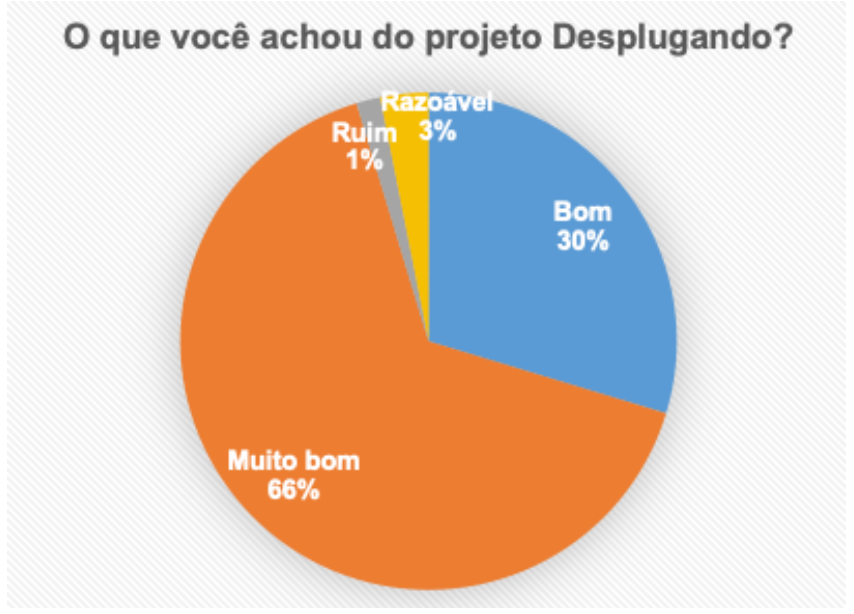

Figura 10. Opinião sobre o projeto

Na segunda pergunta, foi permitido marcar mais de uma opção, de acordo com a evolução do aluno no decorrer do projeto. As respostas são apresentadas na Figura $11 \mathrm{em}$ quantidades absolutas. Destacamos a maior parte das respostas para aptidões importantes em um ambiente educacional e, futuramente, em um ambiente de trabalho: falar em público, trabalhar em equipe e ser criativo.

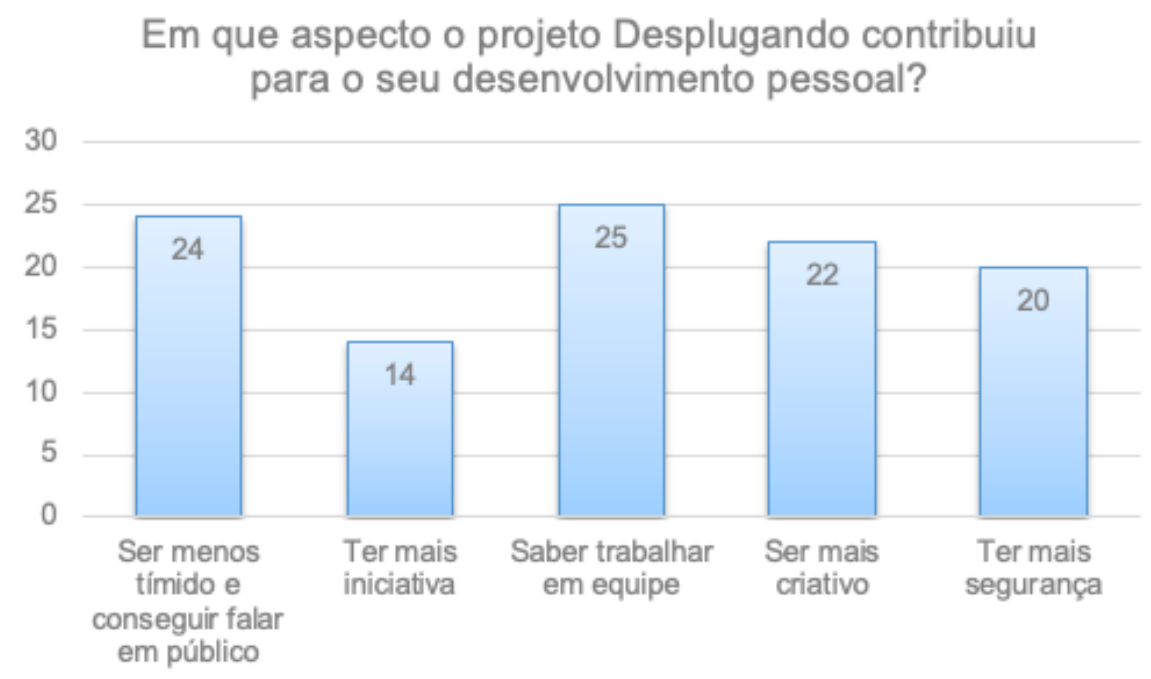

Figura 11. Contribuição do projeto

$\mathrm{Na}$ terceira pergunta, o aluno deveria informar se gosta da metodologia dos professores. Tivemos $97 \%$ para a resposta sim, enquanto para a resposta não, foi obtido $3 \%$. $\mathrm{Na}$ quarta pergunta, o aluno respondeu se conseguiu superar as dificuldades encontradas, 
durante o projeto, como nas atividades que eram mais complexas e, até mesmo, na compreensão do conteúdo. Tivemos $97 \%$ para a resposta sim, enquanto para a resposta não, foi obtido 3\%. No caso, não foi coincidência as mesmas porcentagens. Os alunos que não conseguiram superar as dificuldades em realizar as atividades foram os mesmos que assinalaram que não aprovavam a metodologia dos professores.

Por último, os alunos escreveram no espaço deixado em branco sobre possíveis melhorias na metodologia e citaram pontos positivos e negativos sobre o projeto. Na Figura 12, é mostrada a sugestão de um dos alunos: “... que os professores fizessem uma aula com computadores inventando jogos e aplicativos e inventar sites”.

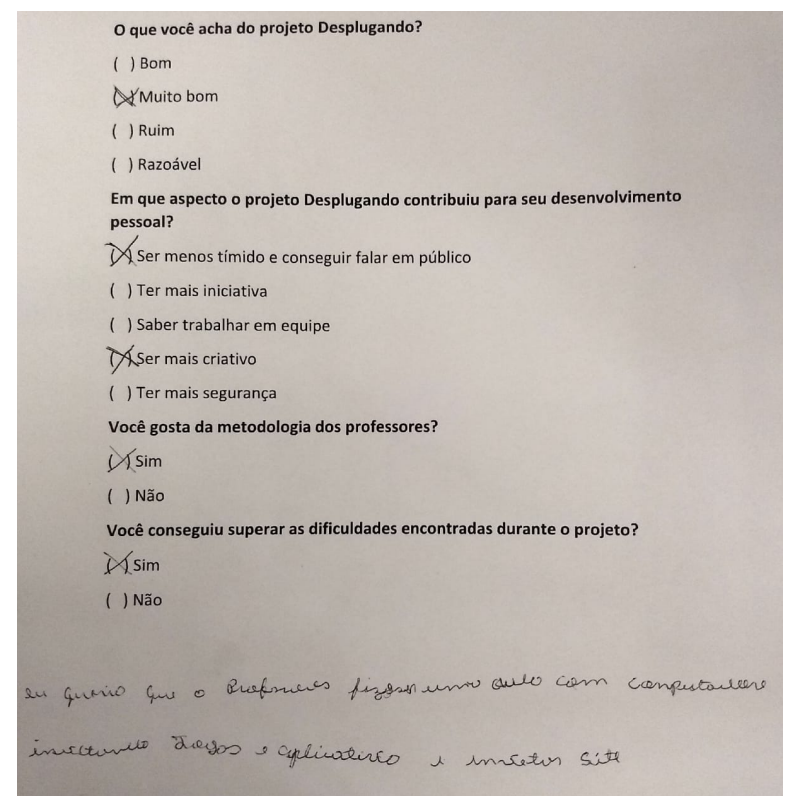

Figura 12. Sugestões por escrito

Essas oficinas serão ofertadas nas próximas edições do projeto, uma vez que a escola não tem computadores suficientes que atendam a todos os alunos, observando o resultado atingido com essa edição, e propondo melhorias na aplicação das atividades. As oficinas de forma desplugada são mais viáveis pois podem ser feitas em sala de aula, com atividades simples e dinâmicas, trabalhando com o raciocínio lógico e que estimulam a criatividade dos alunos. Além disso, o projeto contribui em aspectos pessoais, conforme já constatado na Figura 11.

\section{Considerações finais}

Este artigo descreveu o relato de experiência do Projeto Desplugando, com a aplicação de oficinas de computação desplugada com alunos do $5^{\circ}$ ano do ensino fundamental de uma escola estadual na cidade de Parnamirim-RN. A escola possui um laboratório de Informática sucateado e sem condições de uso, evidenciando a aplicação da computação desplugada, trabalhando o raciocínio lógico dos alunos sem o uso de computadores.

Os alunos que, até então, não tinham acesso a nenhum ensino voltado a área da computação, tiveram a oportunidade de conhecer mais sobre a mesma e com um diferencial, pois, para o entendimento da lógica computacional não se fez uso de nenhum dispositivo eletrônico, tornando-se de baixo custo e grande aprendizado. Além disso, por ser um assunto 
novo e com atividades atrativas, os alunos apresentaram entusiasmo e participaram de todas as oficinas propostas pelo projeto.

Por meio do projeto, os alunos puderam despertar o interesse sobre a Informática e o leque de oportunidades que ela oferece. Além disso, foi possível trabalhar lado a lado com educadores em uma escola pública, fazendo com que o que foi visto em sala de aula, possa ser levado para crianças que futuramente poderão fazer um curso na área tecnológica.

\section{Referências}

Amaral, H. J. C. et al. (2014) "A disseminação do pensamento computacional na educação básica: lições aprendidas com experiências de licenciandos em computação”, Anais do XXXIV Congresso da Sociedade Brasileira de Computação (CSBC).

Bell, T. et al. (2009) "Computer science unplugged: School students doing real computing without computers", The New Zealand Journal of Applied Computing and Information Technology, v. 13, n. 1, p. 20-29.

Bell, T.; Witten, I. H.; Fellows, M. (2015) “Computer Science Unplugged”, disponível em https://classic.csunplugged.org/books. Acesso em 20/09/2019.

Bezerra, G. et al. (2017) "Ensino de computação no ensino médio utilizando técnicas da Computação Desplugada: um relato de experiência", Anais do II Congresso sobre Tecnologias na Educação (Ctrl+E 2017).

Castro, A. (2017) “A importância de estimular o ensino da lógica, tecnologia e matemática às nossas crianças", Disponível em https://medium.com/neworder/a-importancia-deestimular-o-ensino-da-logica-tecnologia-e-matematica-as-nossas-criancasce3818b0f678. Acesso em 20/09/2019.

Guia do Estudante (2019), "Brasil está em penúltimo lugar em ranking de qualidade na Educação", disponível em https:/guiadoestudante.abril.com.br/universidades/brasil-estaem-penultimo-lugar-em-ranking-de-qualidade-na-educacao/. Acesso em 25/09/2019.

Lewin, K. (1946) “Action research and minority problems”, Journal of Social Issues, n. 2, p. Journal of Social Issues 34-36.

Lopes, A.; Ohashi, A. (2019) "Estimular o Pensamento Computacional através da Computação desplugada aos alunos do Ensino Fundamental", Anais do Workshop de Informática na Escola, p. 424.

Marinho, A. R. S. et al. (2018) "Relato de Experiência Vivenciada no PIBID sobre a Utilização da Computação Desplugada, a Hora do Código e do Scratch no Ensino Médio", Anais do XXVI Workshop sobre Educação em Computação.

Papert, S.; Harel, I. (1991) "Situating constructionism”, Constructionism, v. 36, n. 2, p. 1-11.

Romero, M.; Vallerand, V.; Nunes, M. A. S. N. (2019) "Almanaque para popularização de Ciência da Computação", disponível em http://almanaquesdacomputacao.com.br/. Acesso em 25/09/2019.

Souza, G. R. et al. (2016) "Saberes e Fazeres da Docência na Licenciatura em Informática: Relato de Experiência das Ações do PIBID”, Anais do Workshop de Informática na Escola, p. 241. 
Souza, G. R. et al. (2019) "Programadores do Amanhã: Introdução ao Pensamento Computacional na Educação Básica", Anais do IV Congresso sobre Tecnologias na Educação (Ctrl+E 2019), p. 454-462, DOI: https://doi.org/10.5753/ctrle.2019.8917.

Tripp, D. (2005), "Pesquisa-ação: uma introdução metodológica", Educação e pesquisa, v. 31, n. 3, p. 443-466.

Wing, J. M. (2006), “Computational thinking”, Communications of the ACM, v. 49, n. 3, p. 33. 